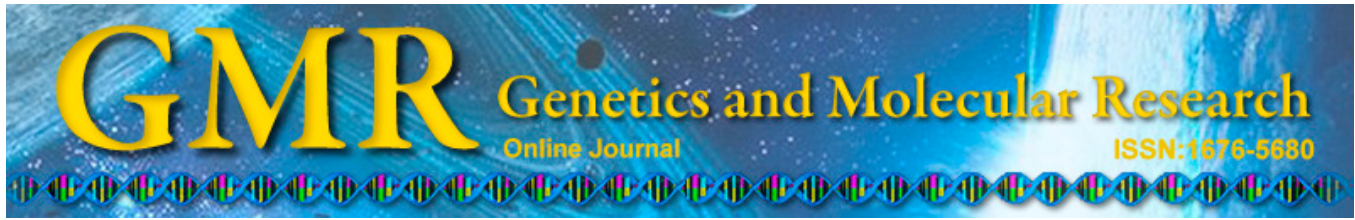

\title{
Effect of DNase treatment on RNA extraction from preimplantation murine embryos
}

\author{
J. Norhazlin', M.N.K. Nor-Ashikin ${ }^{1,2}$, B.P. Hoh' ${ }^{3}$, S.H. Sheikh Abdul Kadir', \\ S. Norita ${ }^{1}$, M. Mohd-Fazirul ${ }^{1}$, W.J. Wan-Hafizah ${ }^{1}$, D. Razif ${ }^{1,2,4}$, M.H. Rajikin ${ }^{5}$ \\ and B. Abdullah ${ }^{2,5}$
}

${ }^{1}$ Institute of Medical Molecular Biotechnology, Faculty of Medicine,
UniversitiTeknologi MARA, Selangor, Malaysia
${ }^{2}$ Maternofetal and Embryo Research Group, Health and Wellbeing CoRe,
UniversitiTeknologi MARA, Selangor, Malaysia
${ }^{3}$ UCSI University Kuala Lumpur Campus, Cheras, Kuala Lumpur, Malaysia
${ }^{4}$ Faculty of Health Sciences, UniversitiTeknologi MARA, Selangor, Malaysia
${ }^{5}$ Faculty of Medicine, UniversitiTeknologi MARA, Selangor, Malaysia

Corresponding author: M.N.K. Nor-Ashikin

E-mail: noras011@salam.uitm.edu.my

Genet. Mol. Res. 14 (3): 10172-10184 (2015)

Received December 1, 2014

Accepted May 11, 2015

Published August 28, 2015

DOI http://dx.doi.org/10.4238/2015.August.28.1

\begin{abstract}
The quality of RNA is crucial when performing microarray experiments. This is particularly important when dealing with preimplantation embryos, from which a minimum yield of RNA of good quality can be produced. We report the optimization of several RNA extraction methods applied to preimplantation embryos at different stages of development. The quality of the samples was confirmed using a microarray and reverse transcription quantitative real-time polymerase chain reaction (RT-qPCR) analysis. A total of 30 cultured two-cell stage embryos of ICR mice were pooled at the 8-cell, morula, and blastocyst stages. The embryos were divided into two groups comprising DNase-
\end{abstract}


treated and non-DNase-treated RNA samples. Total RNA was extracted using a Pico Pure RNA Isolation Kit following the manufacturer protocol, with some modifications. Lysed samples were bound to a silica-based filter, treated with deoxyribonuclease I (DNase I), and washed several times before elution. RNA concentration and integrity were evaluated using an Agilent 2100 Bioanalyzer and an RNA 6000 Pico Assay kit. Although concentrations of non-DNase-treated RNAs were higher than DNase-treated RNA, DNase-treated RNA gave a higher RNA integrity number compared with non-DNase-treated RNA. Inclusion of DNase treatment in the RNA extraction procedure gave the best quality RNA samples from preimplantation embryos, as validated by microarray and RT-qPCR quality control.

Key words: RNA extraction; Preimplantation murine embryos; DNase treatment; Bioanalyzer; Microarray; RT-qPCR

\section{INTRODUCTION}

Microarray technology has been used to explore transcriptional profiles and to acquire molecular expression signatures of normal or diseased cells (Xiang et al., 2003). The reproducibility and reliability of microarray results are dependent on several factors such as array production, extraction of RNA samples, probe labeling, hybridization conditions, and image analysis (Schuchhardt et al., 2000). Microarray relies greatly on the quality of the RNA samples, and the sample processing and labeling techniques used (Vernon et al., 2000).

Evaluation of RNA quality and purity are important steps prior to microarray or quantitative real-time polymerase chain reaction (RT-qPCR) analysis, especially when using preimplantation embryos, which are very limited samples of doubtful RNA quality (Payton et al., 2010). Bustin and Nolan (2004a) and Pfaffl (2005) have reported that there are some criteria that should be followed during RNA extraction procedures to obtain protein- and gene-free RNA that is not degraded, and does not contain enzymatic inhibitors or nucleases.

Currently, there are several commercial methods for RNA extraction of very limited and small samples such as single cells or small amounts of tissue. Three major techniques commonly used for RNA extraction are organic extraction (phenol/guanidine isothiocyanatebased solution), silica membrane technology, and paramagnetic particle technology (Tavares et al., 2011). Silica membrane column technology RNA extraction, which does not require the use of toxic organic solutions, is relatively simple, efficient, and affordable, and involves little contamination of the RNA, is the most commonly used technique. Nevertheless, this method often involves a substantial amount of genomic contamination (Tavares et al., 2011). The use of deoxyribonuclease I (DNase I) treatment during RNA extraction has been employed to remove genomic contamination in many studies (Alkhalil et al., 2010; Larman et al., 2011). However, the performance of DNase I on embryonic samples has yet to be elucidated. In this method, DNase I enzyme is used to degrade DNA contamination in RNA samples by nonspecifically cleaving DNA to release 5'-phosphorylated di-, tri-, and oligonucleotide products (Vanecko and Laskowski, 1961).

The use of RNA in gene expression studies has been widely applied in molecular embryology for more than a decade to improve assisted reproductive technology. Owing to its 
fragile nature, RNA is easily degraded if mishandled during processing. In gene expression studies, RNA of high quality and integrity is essential for obtaining reproducible results. In this report, we optimized RNA extracted from preimplantation embryos using several methods, and found that DNase treatment produced the highest quality RNA. We conducted a comparative analysis of DNase-treated RNA and non-DNase-treated RNA samples extracted from preimplantation embryos at the 8-cell, morula, and blastocyst stages.

\section{MATERIAL AND METHODS}

\section{Source of embryos}

Female ICR mice (6-10 weeks old) were used in this study. Ethical approval (ACUC17/2011) was obtained for the animal experiments. Females were superovulated by intraperitoneal injection of 10 IU pregnant mare's serum gonadotropin, followed by 10 IU human chorionic gonadotropin, $48 \mathrm{~h}$ apart. Superovulated females were then cohabited with stud ICR males at a ratio of $1: 1$. The females were euthanized and used as embryo donors by removing oviducts $48 \mathrm{~h}$ later. Two-cell stage embryos were flushed from the oviducts in M2 medium (SigmaAldrich, USA) using a 29-G needle. They were cultured in $100 \mu \mathrm{L}$ droplets of M16 medium (Sigma-Aldrich) supplemented with 5\% bovine serum albumin, and overlaid with mineral oil. Embryo culture was conducted in a 5\% $\mathrm{CO}_{2}$ incubator at $95 \%$ humidity. The cultured 8-cell, morula, and blastocyst embryos were collected after 19-22, 38-40, and 70-72 h, respectively.

\section{RNA extraction}

Thirty embryos each from the 8-cell, morula, and blastocyst stages were collected and pooled for RNA extraction using TRIzol (Invitrogen, USA), an RNeasyMini Kit (Qiagen, USA), a NucleoSpinkit (Macherey-Nagel, USA) and an Arcturus Pico Pure RNA Isolation Kit (Molecular Devices, USA), with some modifications to the manufacturer protocols. According to the PicoPure kit protocol, embryos were washed twice on a 24-well plate with cold phosphate-buffered saline and added directly to $100 \mu \mathrm{L}$ lysis buffer for 30-min incubation at $42^{\circ} \mathrm{C}$. The samples were homogenized and vortexed for $30 \mathrm{~s}$, then centrifuged at $3000 \mathrm{~g}$ for 2 min to collect lysates. A total of $100 \mu \mathrm{L} \mathrm{70 \%} \mathrm{ethanol} \mathrm{was} \mathrm{added} \mathrm{and} \mathrm{mixed} \mathrm{by} \mathrm{pipetting} \mathrm{up}$ and down 15 times. A new column was treated with the condition buffer for $5 \mathrm{~min}$ at room temperature. The mixture was then transferred into the treated new column and centrifuged for $2 \mathrm{~min}$ at $100 \mathrm{~g}$, followed by $1 \mathrm{~min}$ at $16,000 \mathrm{~g}$. Without removing the flow through, $100 \mu \mathrm{L}$ buffer W1 was added into the column and centrifuged at $8000 \mathrm{~g}$ for $1 \mathrm{~min}$. DNase Treatment (Qiagen) was carried out by incubating $5 \mu \mathrm{L}$ RNase-free DNase I with $35 \mu \mathrm{L}$ RDD buffer for 15 min directly on the filter column. This was followed by washing with $40 \mu \mathrm{L}$ Wash Buffer I. RNA was then eluted with $20 \mu \mathrm{L}$ elution buffer and checked for quality.

\section{RNA quality assessment and statistical analysis}

The concentration and quality of the RNA samples were evaluated using a NanoDrop spectrophotometer (Thermo Scientific, USA) and an Agilent 2100 Bioanalyzer with an RNA 6000 Pico Assay kit (Agilent Technologies, USA). From the NanoDrop results, concentration, $260 / 280$ ratio, and 260/230 ratio of the RNA samples were collected from the different RNA 
extraction kits. The electropherograms of the Bioanalyzer data were compared visually with the control samples. Concentration, ratio of $28 \mathrm{~S}: 18 \mathrm{~S}$, and RNA integrity number (RIN) were analyzed using the Mann-Whitney test by comparing RNA samples with and without DNase treatment from the different embryonic stages separately.

\section{Reverse transcription quantitative real-time polymerase chain reaction (RT-qPCR) expression analysis}

Complementary DNA (cDNA) for the microarray was used for the RT-qPCR analysis to countercheck the RNA quality by quantifying the expression level of glyceraldehyde 3-phosphate dehydrogenase (GAPDH). SsoAdvanced SYBR Green Master Mix (Bio-Rad Laboratories) was used following the manufacturer's protocol for each reaction. Primer sequences for GAPDH were as follows: forward (TGACCTCAACTACATGGTCTACA), and reverse (CTTCCCATTCTCGGCCTTG). The PCR assay was conducted using a CFX BioRad Thermocycler (Bio-Rad Laboratories) with $20 \mu \mathrm{L}$ reaction mixture. Amplification was performed for $30 \mathrm{~s}$ at $95^{\circ} \mathrm{C}$, followed by 39 cycles of $5 \mathrm{~s}$ at $95^{\circ} \mathrm{C}, 10 \mathrm{~s}$ at $60.7^{\circ} \mathrm{C}$, and $5 \mathrm{~s}$ at $65^{\circ} \mathrm{C}$ to $5 \mathrm{~s}$ at $95^{\circ} \mathrm{C}$, with increments of $0.5^{\circ} \mathrm{C}$.

\section{Microarray analysis}

cDNA conversion and amplification were carried out using an Ovation Pico Whole Transcriptome Amplification System kit (NuGEN Technologies, USA) with RNA concentration of $500 \mathrm{pg}$ for all samples. Samples were fragmented, labeled, and hybridized on a GeneChip ${ }^{\circledR}$ Mouse Gene 1.0 ST Array (Affymetrix, USA) according to the manufacturer's instructions. The microarray data were analyzed for quality control (QC) using the Expression Console software (Affymetrix). The positive $v s$ negative value of area under curve (AUC) and Spearman correlation map from each dataset were obtained.

\section{RESULTS}

In this study, RNA was extracted from preimplantation embryos using several RNA extraction kits to compare which method gave the best quality and concentration of RNA (Table 1). Based on the NanoDrop readings, the Pico Pure RNA Isolation kit showed the most reliable values of 260/280 ratio and 260/230 ratio for all embryonic stages. The DNase treatment was not used during the optimization of the Pico Pure extraction method.

After optimization with the Pico Pure extraction method, the quality, purity, and integrity of RNA samples were evaluated. Total RNA quality for each embryonic stage was evaluated based on the lab-on-chip technology of gel electrophoresis. Next, the integrity and quality of the RNA were further verified by performing microarray and RT-qPCR analyses.

\section{RNA assessments}

An optical density measurement of RNA obtained from the Bioanalyzer (Agilent Technologies) was used to assess RNA quality and yield. An electropherogram of good-quality RNA is shown in Figure 1; the control graph includes the three significant peaks (the marker peak, the $18 \mathrm{~S}$ peak, and the $28 \mathrm{~S}$ peak). The electropherogram of DNase-treated samples 
showed two clear peaks corresponding to $18 \mathrm{~S}$ and $28 \mathrm{~S}$ ribosomal RNA (Figure 2D, E and F), as well as the marker peak. However, all non-DNase-treated sample electropherograms showed interference with many noise peaks, indicating chemical or salt contamination of the RNA samples (Figure 2A, B, and C). However, the electropherograms were not sufficient to predict good-quality RNA. Therefore, we used concentration, 28:18S ratio, and RINs from the Bioanalyzer results (Table 2) to identify good-quality samples.

Table 1. Details of RNA samples extracted from 8-cell, morula and blastocyst stage embryos using four commercially available RNA extraction kits.

\begin{tabular}{llccc}
\hline Embryo stage & Type of kit & Concentration & $260 / 280$ & 1.43 \\
\hline 8-cell & Trizol & 15.95 & 1.55 & 1.91 \\
Morula & Trizol & 80.44 & 1.42 & 0.31 \\
Morula & Trizol & 24.25 & 1.42 & 0.31 \\
Morula & Trizol & 43.06 & 1.45 & 0.27 \\
Blastocyst & Trizol & 12.80 & 1.69 & 0.13 \\
Blastocyst & Trizol & 29.76 & 2.06 & 0.25 \\
Blastocyst & Trizol & 46.86 & 1.76 & NA \\
8-cell & Qiagen & 0.25 & 1.94 & NA \\
8-cell & Qiagen & 12.11 & 1.51 & NA \\
8-cell & Qiagen & 1.37 & 1.18 & NA \\
Morula & Qiagen & 1.60 & 1.19 & NA \\
Blastocyst & Qiagen & 0.97 & 1.65 & NA \\
Blastocyst & Qiagen & -1.30 & 35.72 & NA \\
Blastocyst & Qiagen & 2.18 & 2.88 & NA \\
8-cell & Nucleospin & 1.88 & 0.97 & NA \\
8-cell & Nucleospin & 3.72 & 1.33 & 1.43 \\
Morula & Nucleospin & 0.55 & 1.50 & 2.16 \\
8-cell & Pico Pure* & 9.60 & 1.42 & 1.30 \\
8-cell & Pico Pure* & 5.39 & 1.49 & 1.25 \\
Morula & Pico Pure* & 6.31 & 1.62 & 1.83 \\
Morula & Pico Pure* & 7.20 & 5.36 \\
Blastocyst & Pico Pure* & 5.42 & 5.86 & \\
Blastocyst & Pico Pure* & & &
\end{tabular}

*DNase treatment was not used with the Pico Pure kit. NA = not available.

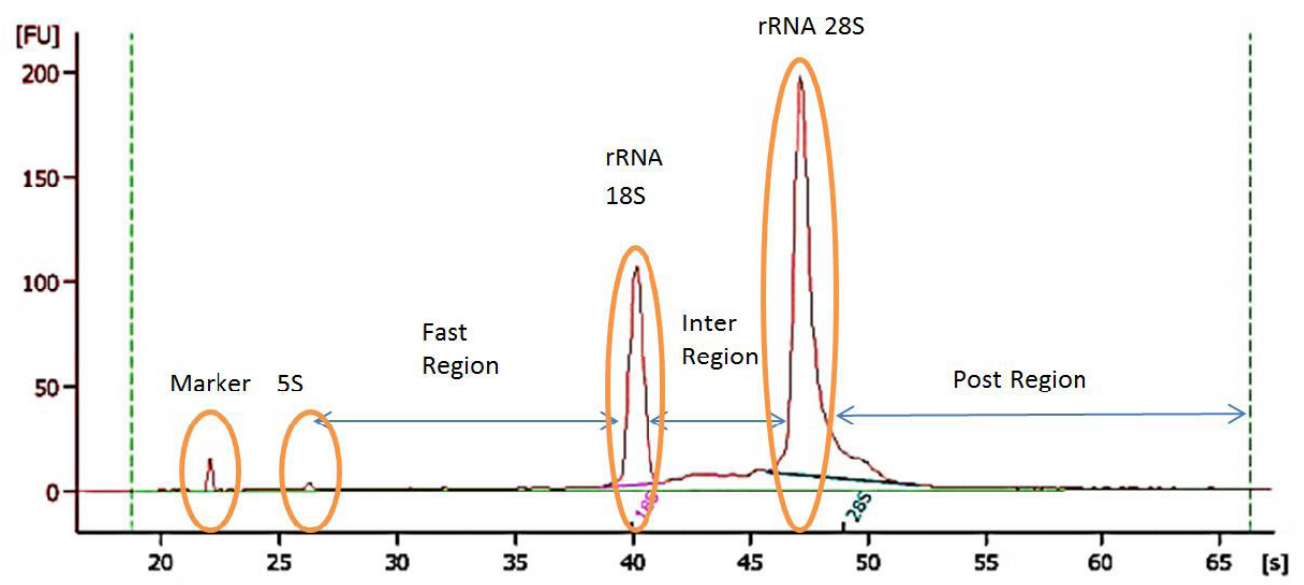

Figure 1. Example of electropherogram with RNA integrity number (RIN) of 10. The four peaks indicated as markers, 5S denotes small RNA, $18 \mathrm{~S}$ and $28 \mathrm{~S}$ denote ribosomal RNA 

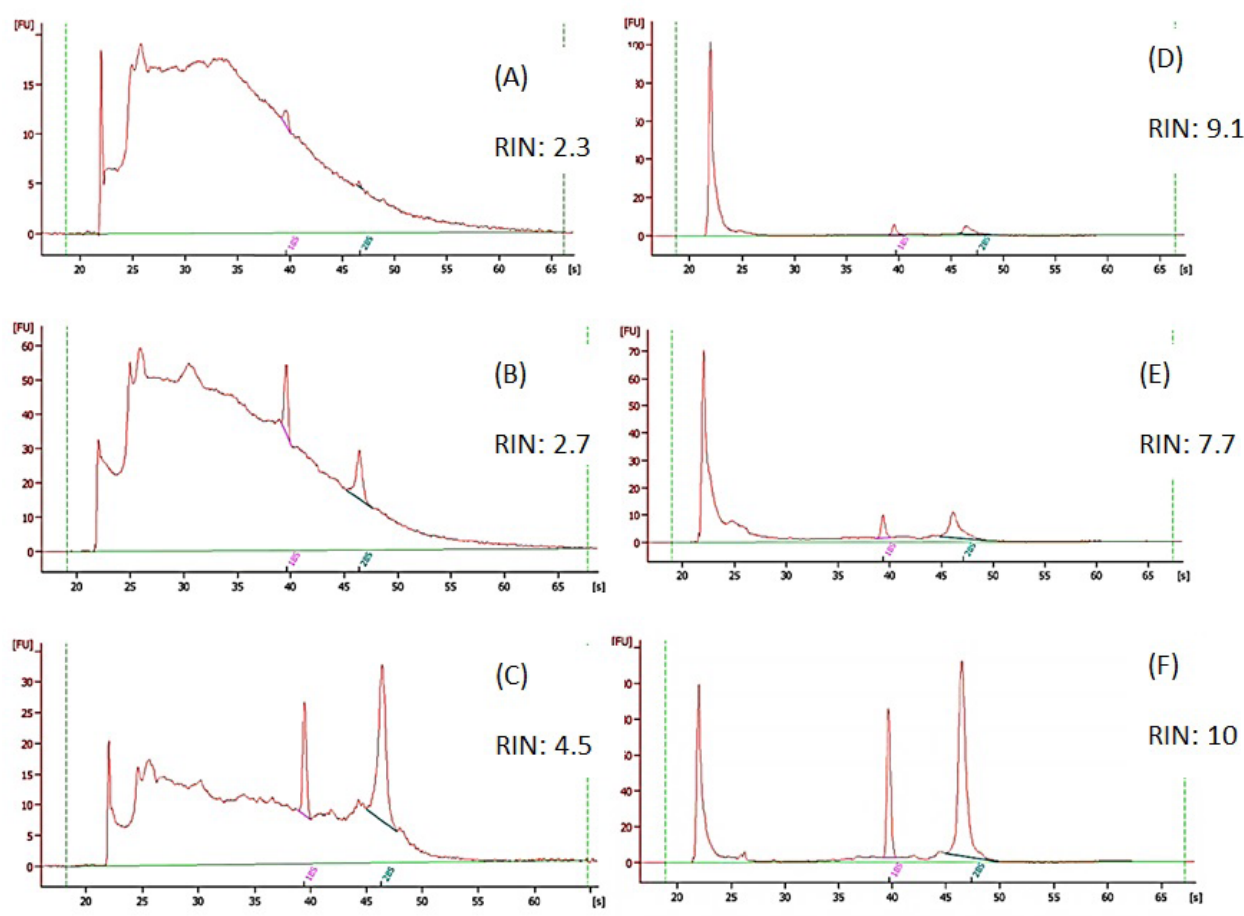

Figure 2. Electropherograms $\mathbf{A}, \mathbf{B}$ and $\mathbf{C}$ are from non-DNase-treated RNA samples of 8-cell, morula and blastocyst stage embryos, respectively. Electropherograms D, E and $\mathbf{F}$ are from DNase-treated RNA samples of 8-cell, morula and blastocyst stage embryos, respectively.

Table 2. Concentrations, $28 \mathrm{~S}: 18 \mathrm{~S}$ ratios and RIN of DNase- and non-DNase-treated RNA samples at 8-cell, morula and blastocyst stage embryos.

\begin{tabular}{lllccc}
\hline Developmental stage & DNase treatment & $\mathrm{N}$ & Concentration $(\mathrm{pg} / \mu \mathrm{L})$ & 28S/18S Ratio & RIN \\
\hline 8 cell & DNase & 4 & $148.5(58.65)$ & $1.25(0.39)$ & $7.73(1.29)$ \\
\multirow{3}{*}{ Morula } & Non-DNase & 2 & $1928(953.18)$ & $0.35(0.35)$ & $2.2(0.14)$ \\
& DNase & 5 & $432.4(213.10)$ & $2.38(0.64)$ & $8.14(0.72)$ \\
Blastocyst & Non-DNase & 3 & $2598.67(1016.80)$ & $0.87(0.25)$ & $2.63(0.12)$ \\
& DNase & 4 & $815.5(214.4)$ & $2.75(0.42)$ & $9.1(1.0)$ \\
& Non-DNase & 4 & $1270.5(499.29)$ & $1.6(0.55)$ & $3.63(0.99)$ \\
\hline
\end{tabular}

Data are reported as means \pm SD.

The concentrations of RNA samples from DNase-treated 8-cell-, morula-, and blastocyst-stage embryos were lower than in the non-DNase-treated samples. In the DNase-treated samples, the blastocyst samples produced the highest RNA concentration. Conversely, in the non-DNase-treated samples, the blastocysts gave the lowest RNA concentration compared with earlier developmental stages (8-cell and morula) (Figure 3). Overall, the 28:18S ratios were higher in the DNase- than in the non-DNase-treated samples (Figure 4). The exception was with the 8-cell stage embryos, where $28: 18 \mathrm{~S}$ ratio of less than 2.0 was observed for both DNase-treated and non-DNase-treated RNA samples. Although not recommended, the successful use of RNA with ratios of less than 2.0 has been reported (Monstein et al., 1995). RINs 
of more than 7 were observed for DNase-treated RNA from the 8-cell embryos, and of more than 8 for DNase-treated RNA from the morulae and blastocysts (Figure 5). The RIN was less than 3 for non-DNase-treated RNA samples at all stages of development. According to Fleige and Pfaffl (2006), an ideal RIN for genomic analysis application is more than 8. In contrast, Agilent Technologies, USA, recommend a standard cut-off RIN of more than 7 for use with their Bioanalyzer. In view of these recommendations, the 8-cell DNase-treated RNA with a RIN of more than 7 was accepted for further analysis.

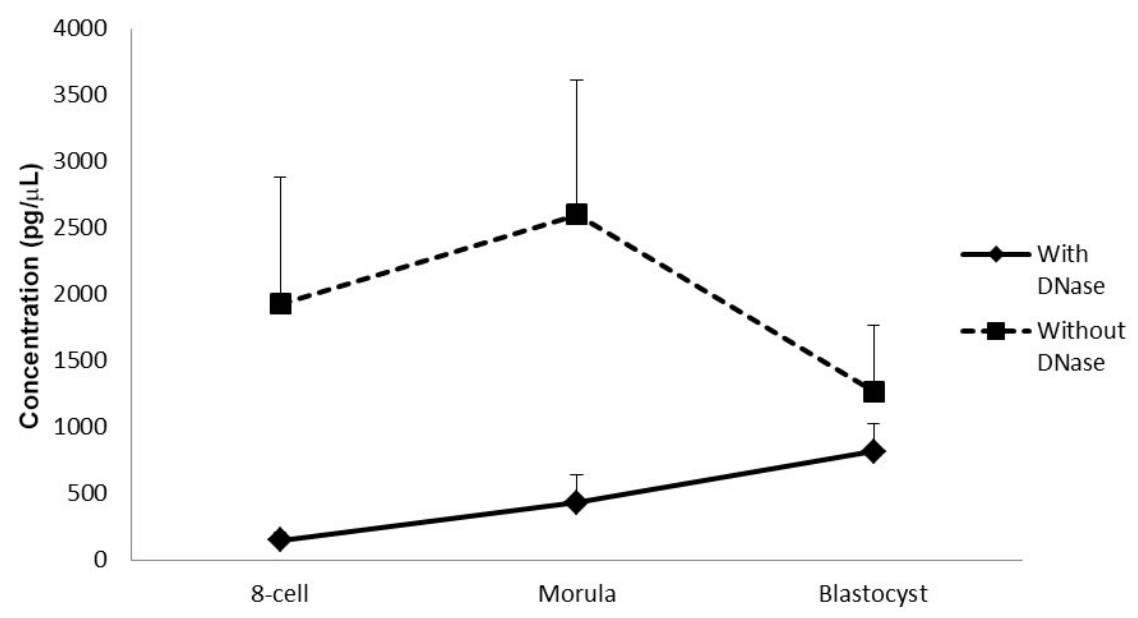

Figure 3. Concentration $(\mathrm{pg} / \mu \mathrm{L})$ for DNase and non-DNase-treated RNA samples from three 8-cell, morula and blastocyst stage embryos. The concentrations were obtained from bioanalyzer data. Data of the graph are reported as means $\pm \mathrm{SD}$.

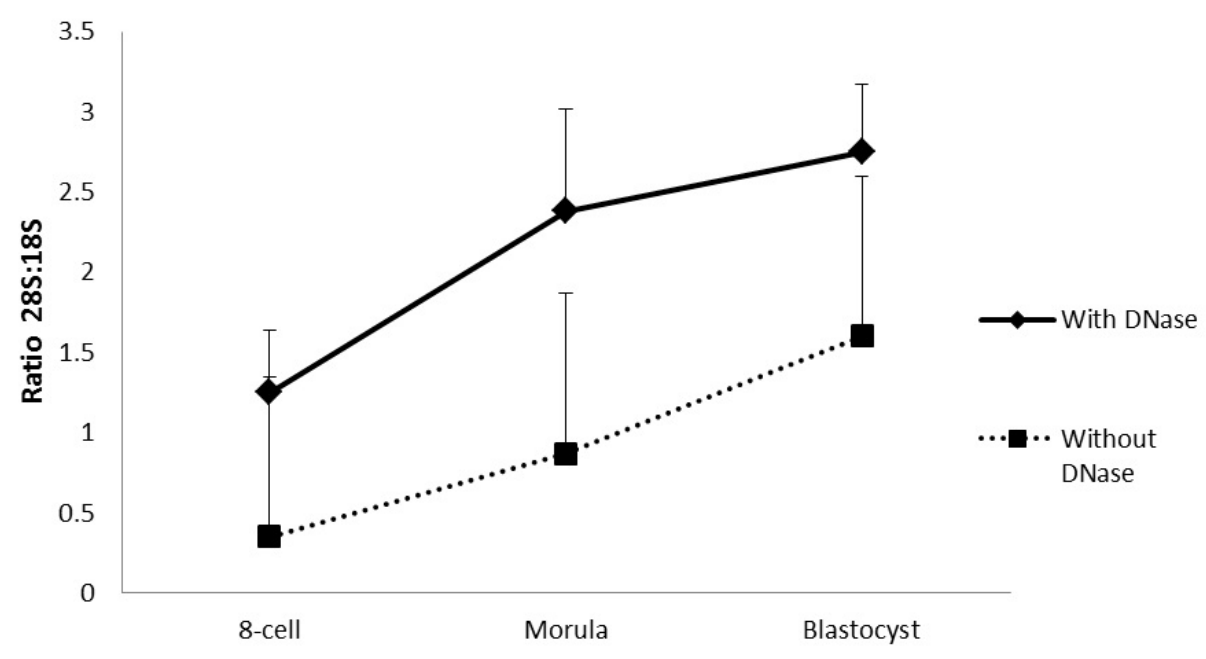

Figure 4. 28:18S ratios for DNase- and non-DNase-treated RNA samples from three 8-cell, morula and blastocyst stage embryos. The 28:18S ratios were obtained from bioanalyzer data. Data are reported as means $\pm \mathrm{SD}$. 


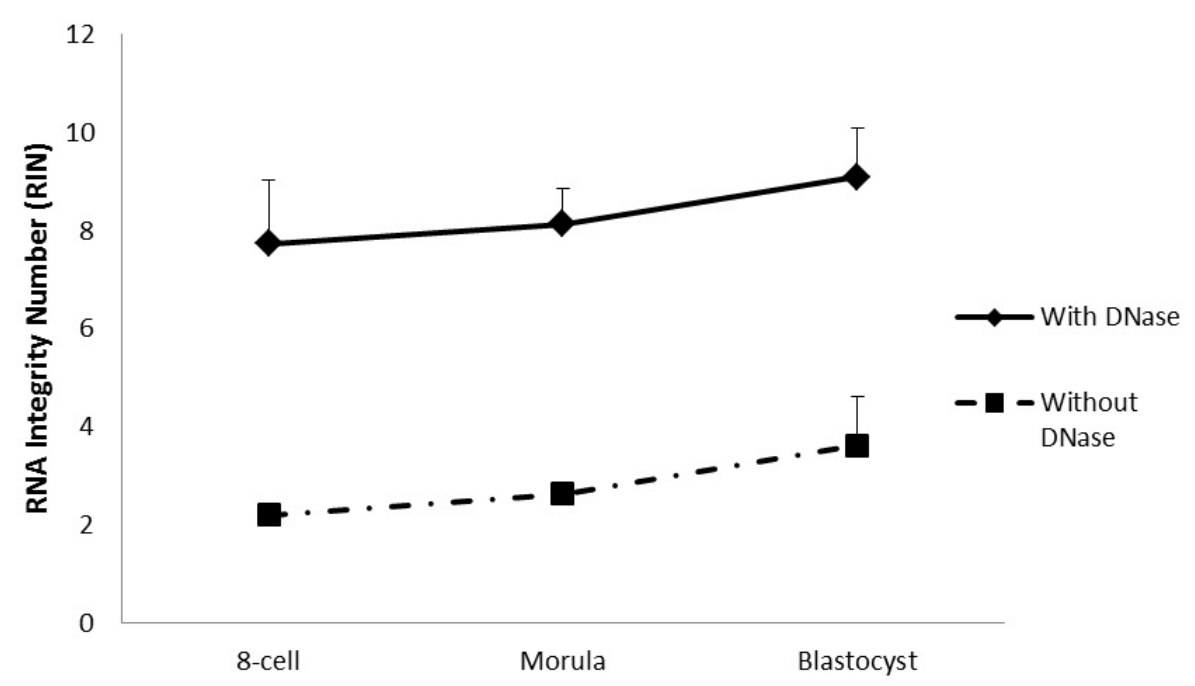

Figure 5. RIN for DNase- and non-DNase-treated RNA samples from three 8-cell, morula and blastocyst stage embryos. RINs were obtained from bioanalyzer data. Data are reported as means \pm SD.

\section{Microarray QC}

Microarray analysis (Affymetrix Mouse Gene ST 1.0 array) showed that the cDNA derived from DNase-treated RNA used in this platform had a positive vs negative AUC of more than 0.89 from the Affymetrix Expression Console, an indication of the QC of the microarray expression data (Table 3). The primary array QC metric at this step was positive $v s$ negative AUC, which parallels signal-to-noise ratio and relates to the ability to distinguish a true signal from noise. A positive $v s$ negative AUC value of $>0.8$ is considered acceptable for array QC metrics in expression analysis (Ericson et al., n.d., ImmGen microarray gene expression data, para. 8). Array-array correlation plots using Spearman correlations analysis for all microarray chips were obtained for QC of the arrays (Figure 6). The correlations between triplicates at each embryo stage were in the highest range, with values of more than 0.90 .

Table 3. Positive versus negative controls of gene expression in the Affymetrix 1.0 ST Array.

\begin{tabular}{lc}
\hline Samples & pos_vs_neg_auc* \\
\hline 8-cell 1 & 0.890052 \\
8-cell 2 & 0.908003 \\
8-cell 3 & 0.918331 \\
Morula 1 & 0.919497 \\
Morula 2 & 0.904185 \\
Morula 3 & 0.922947 \\
Blastocyst 1 & 0.914067 \\
Blastocyst 2 & 0.909394 \\
Blastocyst 3 & 0.911788 \\
\hline
\end{tabular}

*Positive versus negative (area under curve). 


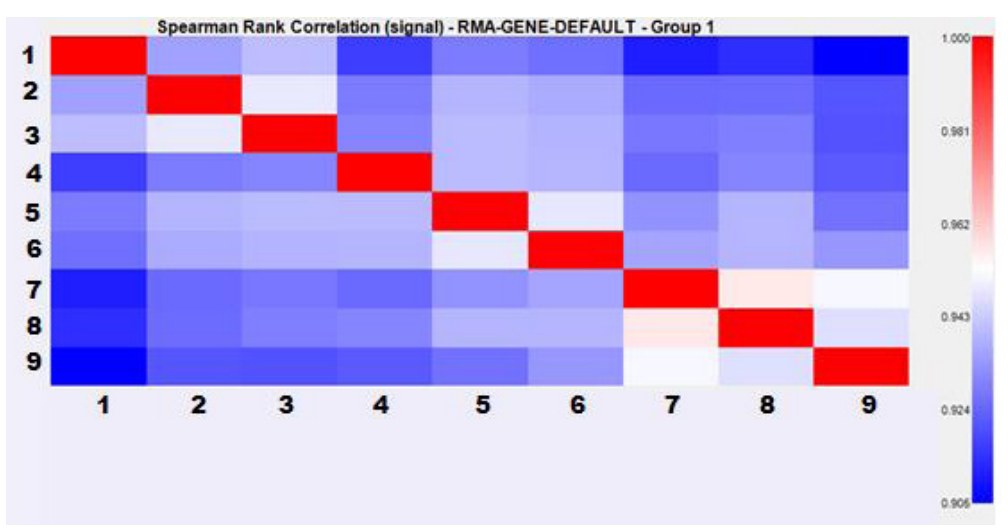

Figure 6. Array-array correlation plot heat maps using Spearman correlation. Correlations between each other of all array samples are shown. The samples were from three developmental stages, with triplicates for every stage. 1-3, 4-6 and 7-9 represent the 8-cell, morula and blastocyst stages of development, respectively.

\section{Transcript abundance measurements}

For RT-qPCR amplification, cDNA derived from DNase-treated RNA samples was investigated using duplicate amplification curves (Cq values) (Figures 7A, B, and C). The amplification time for the triplicates of each sample occurred at approximately the same $\mathrm{Ct}$ value, indicating good-quality DNA (Zakaria et al., 2013).

Expression profiles of the common reference gene $G A P D H$ from DNase-treated cDNA derived from of 8-cell, morula, and blastocyst stages were investigated using RT-qPCR (Figures 8A, B and C). Relative quantities of transcript abundance of the GAPDH gene were shown to be more than 0.5 for both biological replicates.

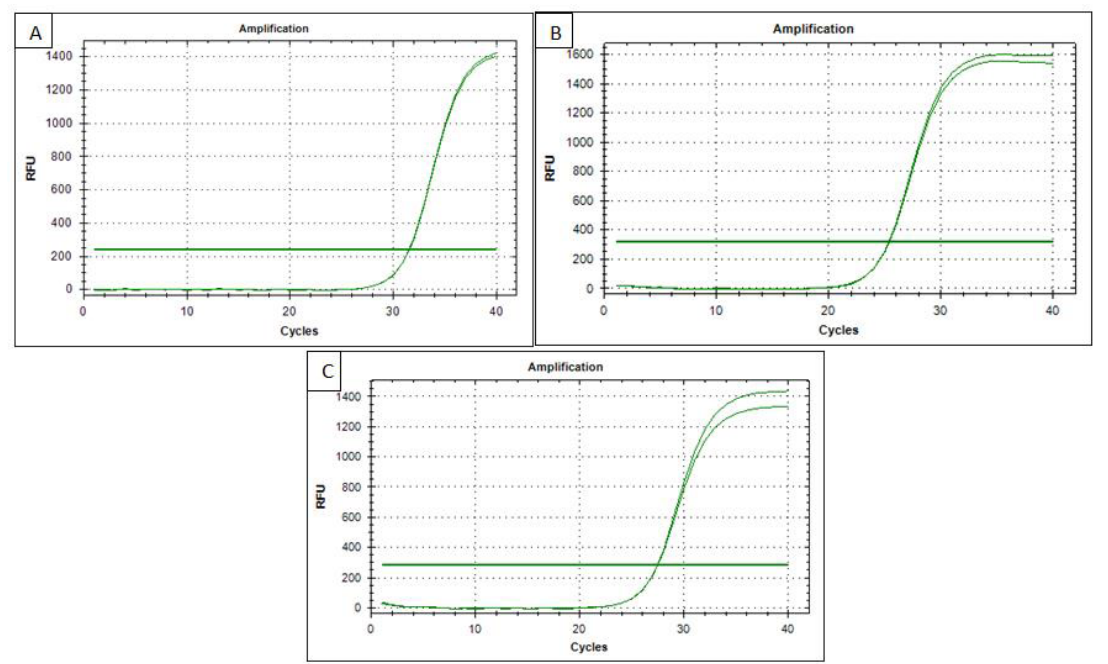

Figure 7. Duplicate amplification curves (Ct curves) of qPCR for RNA extracted from preimplantation embryos at the 8-cell (A), morula (B) and blastocyst (C) stages. All the Ct curves are expression of the GAPDH gene. The curves for both replicates of $\mathrm{Ct}$ curves are shown very close to each other. 
A

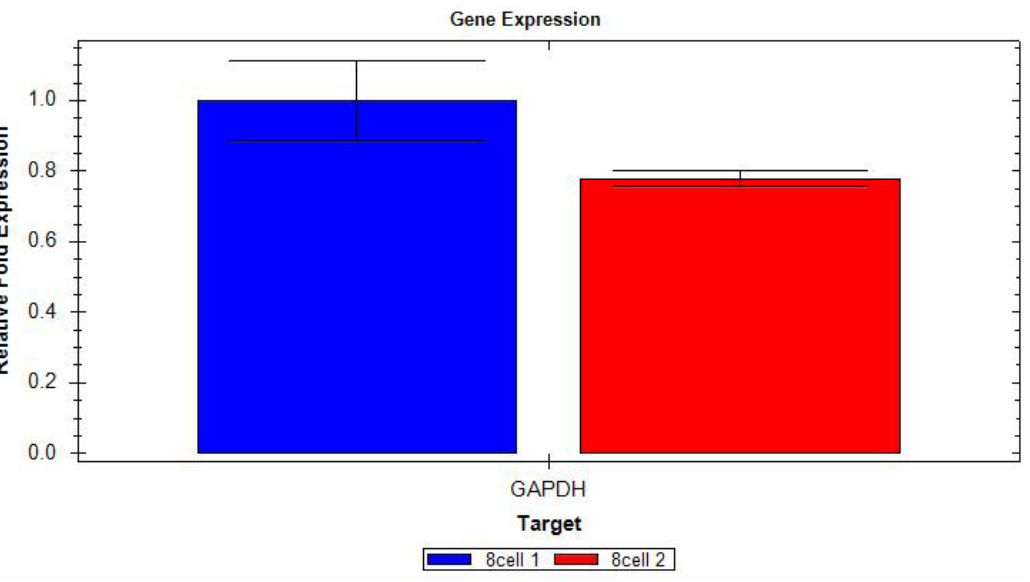

B

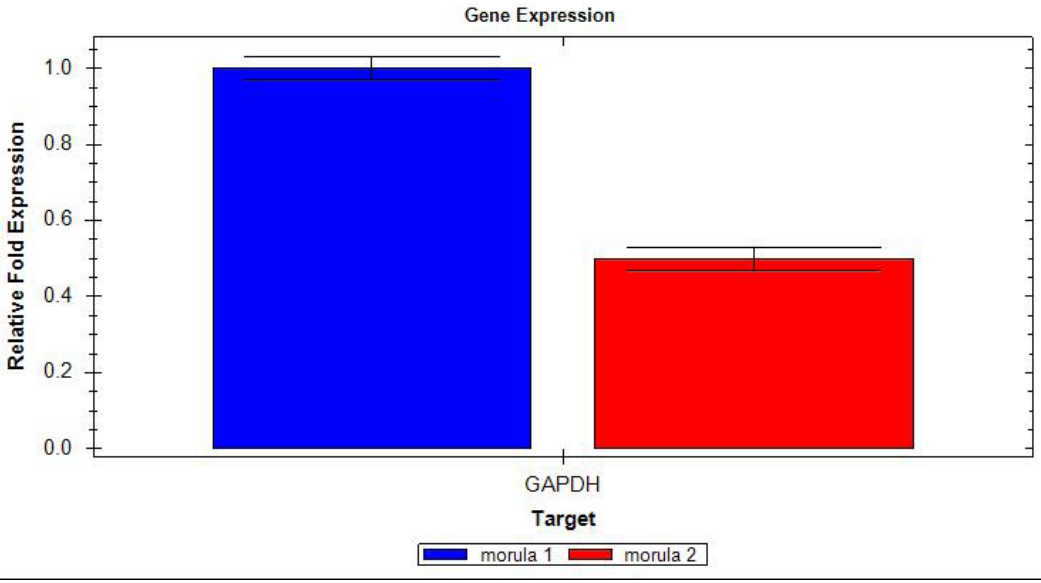

C

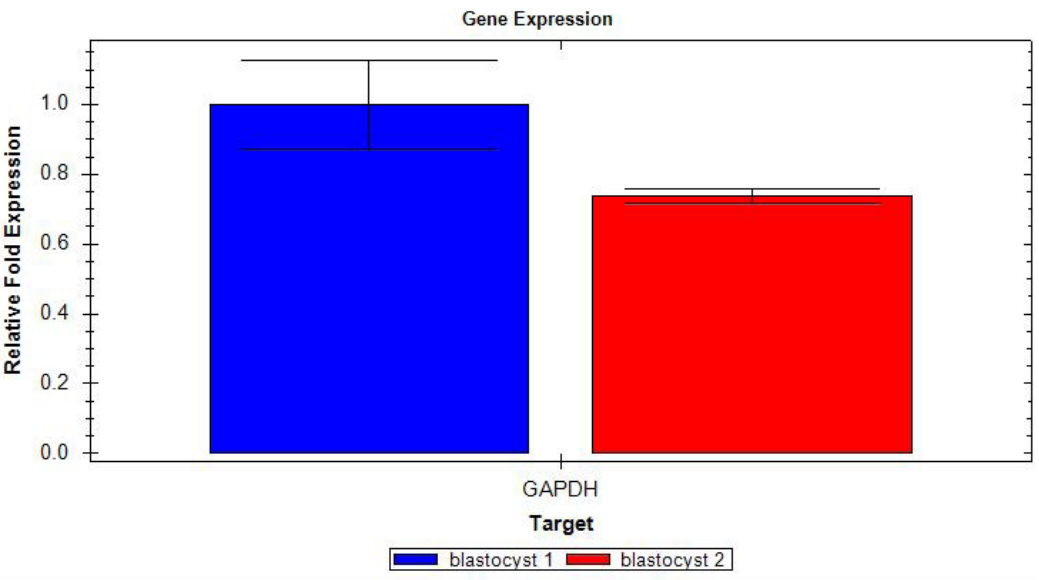

Figure 8. Transcript levels of the GAPDH gene from the 8-cell embryo (A), morula (B) and blastocyst (C). 


\section{DISCUSSION}

Performing a microarray analysis using scarce samples is often challenging, especially when only a limited number of cells are available. Having high-purity RNA of acceptable yield is always the success-determining factor. The pooling of many embryo samples for RNA extraction is not advisable, as it may lead to increased biological variation from the different mouse embryo donors. Therefore, minimizing the number of embryos used for extraction is essential. With all gene expression platforms, an accurate determination of RNA concentration is crucial to avoid any misinterpretation due to genomic DNA contaminants. Hence, the use of DNase I to digest genomic DNA contaminants produces better results. However, the use of DNase I is not without disadvantages. Residual RNase from the DNase treatment will degrade RNA samples, and may affect their long-term storage and reduce the RNA yield (Bustin, 2002). Our study showed that DNase-treated RNA samples were of good quality, albeit with a reduced concentration. Although several commercial methods can amplify and augment total RNA, adequate final concentrations of total RNA remains a concern prior to microarray analysis. To overcome the problem of reduced RNA concentration, the Ovation Pico Whole Transcriptome Amplification System kit (NuGEN Technologies, USA) was used in this study. This kit allows for linear isothermal amplification of cDNA, and has been used successfully in many embryonic development studies (Gilbert et al., 2010; Larman et al., 2011).

Other commercial column-based RNA purification methods, such as Strategene's Absolute RNA, produced significant leftover DNA contamination (Bustin, 2002). Similarly, in this study, non-DNase-treated RNA samples showed residual DNA contamination. Peters et al. (2004) also employed two types of DNase treatment during RNA extraction using spin columns. They found that DNase treatment can be used either within the solution or directly on spin columns. The Pico Pure RNA Isolation kit used in this study was specifically designed for low RNA content samples with low elution volumes. The use of this kit followed by DNase treatment during the RNA extraction has been reported in several gene expression studies of early embryos (Vallée et al., 2009; Larman et al., 2011). As also shown in this study, DNase I digestion is an effective method for removing DNA contamination from RNA samples, and hence produced efficient cDNA synthesis (Tavares et al., 2011).

Although the concentration of DNase-treated RNA was low, two clear bands of $18 \mathrm{~S}$ and 28S ribosomal RNA were observed. In contrast, for non-DNase-treated RNA, the DNA contaminants introduced noise peaks at the fast region, inter region, and post region of the electropherograms, subsequently influencing the purity and integrity of the RNA. According to Imbeaud et al. (2005), a broad band at the inter region indicates DNA contamination. Based on our results, we recommend the use of DNase treatment with column-based RNA extraction when dealing with small samples such as embryos. In this study, RNA extraction from the early embryonic 8-cell-stage embryos gave lower quality RNA compared with the more advanced (post-compaction) stages of morulae and blastocysts, which had greater numbers of cells. The overall quality data for DNase-treated RNA samples were RINs of 7-10 and concentrations of 148-820 pg/ $\mu \mathrm{L}$. Concentrations of RNA samples from the 8-cell, morula, and blastocyst stages were adequate to perform cDNA amplification and subsequent gene expression analysis by microarray and RT-qPCR.

The quality of DNase-treated RNA samples was validated by microarray and RTqPCR. For microarray, the primary array QC metric from positive $v s$ negative control of AUC with a value of more than 0.8 for all samples was accepted for further gene expression analy- 
sis. An AUC of 1.0 indicated absolute distinction between data, and 0.5 indicated no separation (Stafford, 2008). Another QC for microarray was array-array correlation plots where all correlation coefficients obtained were more than 0.90 . This range was ideal and problems such as high noise and low signal intensity were not encountered. For RT-qPCR, the quantitation of the transcript levels of the common housekeeping gene GAPDH was carried out for two RNA samples from each developmental stage. A successful and meaningful quantitative mRNA analysis using the RT-qPCR method requires intact RNA (Fleige et al., 2006). However, in this study, one RNA sample from each stage showed higher levels of the transcripts. Sometimes, the intact RNA does not assure good RT-qPCR results because RNA samples may contain inhibitors that reduce reaction assay efficiency (Bustin and Nolan, 2004b; Wong and Medrano, 2005).

In conclusion, we recommend DNase treatment when extracting RNA from limited samples such as the preimplantation embryo, even when using column-based methods, as it provides RNA of high quality and acceptable yield for further analysis.

\section{Conflicts of interest}

The authors declare no conflict of interest.

\section{ACKNOWLEDGMENTS}

The authors would like to express sincere appreciation to members of the Institute of Medical Molecular Biotechnology (IMMB) and the Laboratory Animal Care Unit (LACU), Faculty of Medicine, UniversitiTeknologi MARA. Research supported by the Malaysian Ministry of Education Fundamental Research Grant Scheme [\#600-RMI/ST/FRGS5/3/ FST(71/210)], a UniversitiTeknologi MARA (UiTM) grant [\#600-RMI/ST/DANA5/3/ Dst(337/2011)] and the Malaysian Ministry of Education Research Acculturation Grant Scheme [\#600-RMI/RAGS 5/3 (91/2013)].

\section{REFERENCES}

Alkhalil A, Hammamieh R, Hardick J, Ichou MA, et al. (2010). Gene expression profiling of monkeypox virus-infected cells reveals novel interfaces for host-virus interactions. Virol. J. 7: 173.

Bustin SA (2002). Quantification of mRNA using real-time reverse transcription PCR (RT-PCR): trends and problems. 29: 23-39.

Bustin SA and Nolan T (2004a). Template Handling, Preparation and Quantification. In: The Real-Time PCR Encyclopedia, A-Z of Quantitative PCR (Bustin SA, ed.). International University Line, La Jolla, 87-120.

Bustin SA and Nolan T (2004b). Pitfalls of quantitative real-time reverse-transcription polymerase chain reaction. $J$. Biomol. Tech. JBT 15: 155-166.

Ericson J, Davis S, Lesh J, Howard M, et al. ImmGen microarray gene expression data: Data Generation and Quality Control pipeline. Available at [https://www.immgen.org/Protocols/ImmGen\%20QC\%20Documentation_ALLDataGeneration_0612.pdf]. Accessed April 14, 2015.

Fleige S and Pfaffl MW (2006). RNA integrity and the effect on the real-time qRT-PCR performance. Mol. Aspects Med. 27: 126-139.

Fleige S, Walf V, Huch S, Prgomet C, et al. (2006). Comparison of relative mRNA quantification models and the impact of RNA integrity in quantitative real-time RT-PCR. Biotechnol. Lett. 28: 1601-1613.

Gilbert I, Scantland S, Sylvestre EL, Dufort I, et al. (2010). Providing a stable methodological basis for comparing transcript abundance of developing embryos using microarrays. Mol. Hum. Reprod. 16: 601-616.

Imbeaud S, Graudens E, Boulanger V, Barlet X, et al. (2005). Towards standardization of RNA quality assessment using user-independent classifiers of microcapillary electrophoresis traces. Nucleic Acids Res. 33: e56. 
Larman MG, Katz-Jaffe MG, McCallie B, Filipovits JA, et al. (2011). Analysis of global gene expression following mouse blastocyst cryopreservation. Hum. Reprod. 26: 2672-2680.

Monstein HJ, Nylander AG and Chen D (1995). RNA extraction from gastrointestinal tract and pancreas by a modified Chomczynski and Sacchi method. Biotechniques 19: 340-344.

Payton RR, Rispoli LA and Edwards JL (2010). General features of certain RNA populations from gametes and cumulus cells. J. Reprod. Dev. 56: 583-592.

Peters IR, Helps CR, Hall EJ and Day MJ (2004). Real-time RT-PCR: considerations for efficient and sensitive assay design. J. Immunol. Methods 286: 203-217.

Pfaffl MW (2005). Nucleic Acids: mRNA identification and quantification. In: Nucleic acids. Encyclopedia of analytical science. 2nd edn. (Worsfold PJ and Galagher PK, eds.). Academic Press, 417-426.

Schuchhardt J, Beule D, Malik A, Wolski E, et al. (2000). Normalization strategies for cDNA microarrays. Nucleic Acids Res. 28: e47.

Stafford P (2008). Methods in microarray normalization. CRC Press, London.

Tavares L, Alves PM, Ferreira RB and Santos CN (2011). Comparison of different methods for DNA-free RNA isolation from SK-N-MC neuroblastoma. BMC Res. Notes 4: 3.

Vallée M, Dufort I, Desrosiers S, Labbe A, et al. (2009). Revealing the bovine embryo transcript profiles during early in vivo embryonic development. Reproduction 138: 95-105.

Vanecko S and Laskowski M Sr (1961). Studies of the specificity of deoxyribonuclease I. III. Hydrolysis of chains carrying a monoesterified phosphate on carbon 5'. J. Biol. Chem. 236: 3312-3316.

Vernon SD, Unger ER, Rajeevan M, Dimulescu IM, et al. (2000). Reproducibility of alternative probe synthesis approaches for gene expression profiling with arrays. J. Mol. Diagn. 2: 124-127.

Wong ML and Medrano JF (2005). Real-time PCR for mRNA quantitation. Biotechniques 39: 75-85.

Xiang Z, Yang Y, Ma X and Ding W (2003). Microarray expression profiling: analysis and applications. Curr. Opin. Drug Discov. Devel. 6: 384-395.

Zakaria Z, Umi SH, Mokhtar SS, Mokhtar U, et al. (2013). An alternate method for DNA and RNA extraction from clotted blood. Genet. Mol. Res. 12: 302-311. 